\title{
ESTABLISHING THE ABILITIES OF EMPLOYEES TO MANAGE WORKING TIME IN VARIOUS ASPECTS OF THE WORK PROCESS
}

\section{Emiliya Duneva ${ }^{2}$}

Received: 28.09.2020, Accepted: 18.10.2020

\begin{abstract}
For the past decade, organizations have been focusing more and more of their efforts on tackling the issue of effective time management and devoting resources to identifying problems in this direction, so that employees can be consulted and relevant innovations can be undertaken in a way that ensures a minimum of loss of working time in activities that do not lead to specific results in the workplace. In this regard, it is quite expected and advisable for managers and employees to focus on a certain minimum of a set of factors that affect the use of time in the workplace. It is imperative to create a system for tracking and evaluating the way employees use the regulated working hours. In this article we define the skills, abilities and the way to manage the time of a representative sample of employees of the company "LILIA 86 OOD".
\end{abstract}

Keywords: time management, work process, Bulgarian managers, time allocation

JEL Codes: J22, J29

\section{Introduction}

Managing the time of employees in modern business is one of the most serious issues among professionals, especially in times of crisis and finds an increasingly serious place in any organization. It is necessary in each employee to look for certain qualities, abilities and skills for proper management of their own working time, which will lead to high results for the organization. Building an indicative profile of employees related to their personal abilities and time management skills, as well as the impact of the above on the overall work process,

\footnotetext{
${ }^{2}$ University of National and World Economy, Sofia, Assistant Professor, $\mathrm{PhD}$, e-mail: eduneva@unwe.bg ORCID ID: https://orcid.org/0000-0003-4292-2989
} 
would reveal the strengths and weaknesses of the organization in this area and thus it would be possible to take the necessary corrective actions. When the balance between personal time management of employees and the organization as a whole is there, then we could talk about successful time management. In this regard, when the waste of time is minimized in an organization, it would inevitably lead to competitive results, with the help of which successful management is achieved. The purpose of the development is to establish the extent to which there is a system for managing the working hours of employees in LILIA 86 OOD, both personally by the employees and by the established internal procedures and rules in this regard. For the purpose of the research we will use the method of the survey.

\section{Layout of the problem}

March 2020 has become emblematic in terms of time management in organizations, which undoubtedly led to stress in the workplace. Unexpectedly, most organizations had to change the way they worked. Whether the Covid-19 crisis will affect daily business tasks negatively or not remains to be seen. About 3 billion people worldwide were under blockade and could not go to their offices. Many managers had to manage their business remotely, and many employees were given the opportunity to write a new page in the list of their competencies. The situation forced the employees to quickly rearrange their tasks, to optimize their business - from production, supply chain, sales, human resources management and other different types of services, financial management, etc. The provided arguments make it possible to conclude that all employees and managers must adapt to the new environment, including employees in the company LILIA 86 OOD Dragoman.

The company was registered in April 2009 with subject of activity: Production and trade in confectionery. Currently, the company maintains and manages two own confectioneries and workshops - one in Sofia and one in Dragoman. Appointed employees 12 pcs

\section{Literature Review}

A time management system is a combination of processes, tools, techniques and methods. Usually time management is a necessity in the development of any project, as it determines the time for its completion and its scope.

In their book: „Human Resources Management” (Harizanova, 2006, p.229), the authors define the management of working time, identifying it with 
„self-controlled experience of using time in a subjectively effective way to achieve certain results”. In his book: „Successful Time Management”, Patrick Forsyth (Forsyth, 2013, p.11-12) defines the general principles of time management as simple and clear. Each individual must do what is important and ignore everything that is not. For him, urgent tasks are tasks that are not properly distributed when they arise. However, oversimplifying tasks does not make them easier to deal with.

In order to continuously monitor the use of working time by employees, it is necessary to introduce constant control over its use. There are various ways to control working hours, the most common nowadays, among which are electronic cards, control systems for access to the workplace, video surveillance and "logging” in the database. However, some of the control tools are limited to reporting the entry and exit of employees at their workplace and do not have a mechanism for recording the actions of employees inside the workplace.

Main problems in consolidating working time

$\checkmark \quad$ Many meetings (including face-to-face and online);

$\checkmark \quad$ Unexpected visitors (unexpected meetings);

$\checkmark$ Incorrect delegation of tasks;

$\checkmark$ Telephone interruptions;

$\checkmark$ Crises;

$\checkmark$ Socialization at the workplace - coffee breaks, cigarettes, conversations with colleagues;

$\checkmark \quad$ Inability to prioritize tasks.

\section{Time management methods}

\section{POSEC method}

In his book: „How to Become Extraordinary Managers”, Dr. Libardo Gonzalez (Gonzalez, 2011, p.79) considers the POSEC method of time management as an acronym, denoting the following main points that are emphasized in its use:
$\checkmark$ Prioritize;
$\checkmark$ Organizing;
$\checkmark$ Streamlining;
$\checkmark$ Economizing;
$\checkmark$ Contributing.

The method builds a template that emphasizes the average values of an individual's primary need for emotional and material security. This shows that by first satisfying the personal responsibilities of an individual, it is then easier for 
him to take collective responsibility. According to the POSEC method, it is necessary to prioritize personal time and the lives of individuals to be determined by clear goals. It is then necessary to organize the tasks that are performed regularly in order for them to be successful. The next step is to streamline tasks that are not liked but need to be done. In addition, it is advisable to reduce the performance of tasks that are pleasant to perform, but not urgent. Finally, it is required to contribute by paying attention to the tasks that really matter.

\section{Eisenhower matrix}

The Time Management Matrix was popularized as a management method by Stephen Covey (1990, pp. 87-88) in his book The Seven Habits of Highly Effective People. It indicates how the whole work can be distributed according to two criteria: how important it is (the vertical axis of the diagram) and how urgent it is (the horizontal axis). As a result of these two criteria, the model creates four squares, which Covey calls quadrants, which represent the key to time management. All tasks are evaluated using the criteria important / not important and urgent / not urgent, and are placed in the defined quadrants.

\section{The Pareto principle}

The Pareto principle (Koch, 1999) is a statistical decision-making technique used for a limited number of tasks that generate a significant overall effect. Pareto's principle is based on the fact that doing $20 \%$ of the work generates $80 \%$ of the advantage of doing all the work. Or in terms of quality improvement, the vast majority of problems ( $80 \%)$ are generated by several key causes $(20 \%)$. The Pareto principle is a formal technique, useful when many possible outcomes of action compete with each other. In essence, the principle assesses the benefits provided by each action and then selects a number of the most effective actions that provide an absolute benefit close to the maximum possible.

\section{Delegation of powers}

According to Richard Luke and Perry Mackintosh (Luecke, 2009, p.56), the authors of the book Handbook for Delegating an Employed Manager are processes in which supervisors and senior managers with direct subordinates assign formal authority and responsibility.

When the number of tasks of the manager exceeds his ability to cope with them, it is necessary to build a system for sharing them. In this way, the delegation of power becomes an important tool for organizational functions.

Obstacles to effective time management 
The main obstacles (Vachkova, 2003, p.15) to the effective management of time, considered by most authors, specialists in the field, can be grouped into the following groups:

\section{1) Lack of priorities}

For the manager, this means not understanding the priorities at work, spending the day reacting to crisis moments, moving from one emergency to another, without a defined plan or group of goals.

2) Indecision or procrastination

Delaying a decision or postponing action makes it difficult for the manager to perform basic responsibilities and can paralyze his ability to perform the required work tasks effectively.

3)Inability to delegate

The reasons for this are numerous and include: lack of training of managers to properly delegate, insecurity on the part of the manager, lack of trust, belief that the manager can do something faster and better, fear that their subordinates will resent the tasks and responsibilities assigned to them.

4)Perfectionism and exceptional attention to detail

This problem is related to the inability to delegate and includes a fixed idea of perfectionism and attention to very small details in all tasks, including trivial ones.

\section{5)Ineffective meetings}

They are one of the most common wastes of time, and managers spend much of their time in meetings of various types.

6)Telephone interruptions

They can upset a person's ability to concentrate and work well.

7)Visits to visitors and non-work-related conversations

They are a significant obstacle in the work of the manager, making it difficult to perform tasks on time. When the focus of the conversation is on something other than the main priorities, such visits are just a waste of time. Networks

8)Rituals related to drinking coffee and smoking and reviewing Social

Depending on the frequency of cigarette and coffee use, considerable time can be wasted during the day. Research shows that up to 1-2 hours a day can be lost from these rituals. In recent years, social networks are literally "eating" time.

9)Inability to say "No"

This is the inability of the manager to refuse some unrelated requests from friends, colleagues, subordinates, superiors and others. 
The ability to properly manage time is a consequence of the use of various methods and techniques for the successful implementation of the process. In each organization, it is advisable to analyze how employees cope with their daily tasks, methods and the tools that they use to deal with time shortages. Based on the results obtained, management could take action to train and improve the way employees spend their working time.

\section{Research}

In order to establish the abilities and the ways of reaction of the employees in different aspects in the management of the working hours in LILIA 86 OOD a survey was conducted. Based on the findings, the strengths and weaknesses of employees regarding the application or non-application of time management methods will be highlighted. For the purpose of the study, a representative random sample of 8 people was made, which represents $80 \%$ of the total number of employees in the company. For the first step of the survey a questionnaire was compiled, consisting of three parts:

The first part consists of questions measuring various aspects of employee time management.

They aim to build a personal profile of the respondents about the ways they practice coping with the tasks in the workplace.

$\checkmark \quad$ The second part consists of questions with listed options, reevaluating aspects of the employees' time.

$\checkmark \quad$ The third part consists of demographic issues.

In the first part, the interviewed employees were asked to assess using a scale from 1 to 5 to what extent the listed situations apply to them.

The main skills that are assessed through the situations presented in the survey in its first part are the following:

$\checkmark \quad$ Concentration in the workplace;

$\checkmark \quad$ Correct distribution of work tasks in order to complete them within the specified period;

$\checkmark \quad$ Regular preparation of a daily to-do list;

$\checkmark \quad$ Ability to prioritize;

$\checkmark \quad$ Ability to combine similar tasks;

$\checkmark \quad$ Ability to communicate properly with colleagues in order to avoid distractions in the workplace;

Correct assessment of the time required to perform a task; 
The main skills that are assessed through the situations presented in the survey in the second part are:

$\checkmark \quad$ Socialization in the workplace;

$\checkmark$ Delegation.

The main indicators for which demographic information is collected for the employees in the third part are: gender, age, level of position.

With the help of the first and second parts of the questionnaire, it is possible to assess the time management factors that employees are able to manage properly and those that need to be improved and paid attention to. The third part aims to gather information about the demographic profile of employees and their level of position. For greater clarity in the article: we also apply the distribution of participants by gender and selected option of question 1 . The distribution for all questions in the questionnaire is made according to the same scheme.

Table. 2. Distribution of participants by gender and selected option of question

1.

\begin{tabular}{|l|r|l|}
\hline \multicolumn{1}{|c|}{ Option } & \% women from total no. & \\
\hline $100 \%$ applies to me & 100 & 0 \\
\hline $75 \%$ applies to me & 50 & 50 \\
\hline $50 \%$ applies to me & 79 & 21 \\
\hline $25 \%$ applies to me & 67 & 33 \\
\hline $0 \%$ applies to me & 100 & 0 \\
\hline
\end{tabular}

Based on the results of the survey, it is clear that $40 \%$ of all employees almost never have to rush at the last minute to complete a task, that is, they manage to cope within the set deadlines. For $24 \%$ of them, however, rushing to complete a task at the last minute is a common phenomenon and applies to them in $75 \%$ of cases. $28 \%$ of all participants never rush at the last minute to complete their assignments. In $83 \%$ of the surveyed women there is a successful handling of all tasks on the agenda. This percentage is significantly lower for men - 17\% of them manage to do everything they planned within the working day. $67 \%$ of the surveyed men often rush to finish their work at the last minute, while this percentage is significantly lower for women (33\%). Of all participants in the study, $48 \%$ managed to complete their tasks within or before the deadline.

The situations listed in the second part of the questionnaire aim to assess the extent of the use of time for socialization in the workplace, as well as the skill and frequency of delegation of powers by employees. 
None of the respondents spends 2 or more hours socializing in the workplace. 32 to 90 minutes are spent by $32 \%$ of the participants in the study, and the highest percentage of all $-48 \%$, spend between 15 and 30 minutes. For $20 \%$ of employees, the minutes for socialization are less than 15 per day. These results show that most often the loss of working time per day is between 15 and 30 minutes, which is why employees have to compensate for this time by staying after work

In all age groups participating in the study, it was observed that most employees spend between 15 and 30 minutes a day socializing. Most employees between the ages of 25 and 30 spend between 60 and 90 minutes a day.

It is advisable for the employer to take measures to limit the loss of working time in meaningless conversations, gossip and discussion of topics that are not related to the work process.

Only $8 \%$ of employees delegate more than $50 \%$ of their tasks, and $36 \%$ delegate a very small percentage. Of all respondents, $44 \%$ delegate about $25 \%$ of their responsibilities. These results clearly highlight the need for additional measures and training in order to familiarize employees with the benefits of delegation as a time management method.

In connection with the use of e-mails for accepting orders, etc., the author of the article has included a question assessing the way of dealing with the receipt and processing of electronic messages. $88 \%$ of the surveyed employees take the time to respond to the messages they receive each time they are received. Only $12 \%$ of participants respond to inquiries received at a specific time each day. This issue also requires attention to be paid to the software used to process electronic messages and the control options it offers. It is recommended that employees undergo special training to work with specialized message processing software to help manage their working hours.

\section{Conclusions from the analysis of the conducted research}

The evaluation of the elements was carried out on three criteria - personal qualities of the leader, professional competencies of the leader and communication culture of the leader. The highest rated elements for each criterion can be included in a list containing characteristics that a management culture should have:

- $\quad$ Responsibility

- Transparency

- Cooperation

- Loyalty 
- Knowledge of the law

- Management experience

- Strategic orientation

- $\quad$ Promoting innovation

- Keeping written correspondence

- $\quad$ Conducting online communications

- $\quad$ Successful negotiations

- Knowledge of nonverbal communication.

The presented list includes the four elements of each criterion, which were most highly rated by the respondents, as important qualities and managerial competencies for the manager. We can conclude that according to the study, these are the elements that should be embedded in the management culture of successful managers.

Table 7. presents the derived elements of the concepts for corporate culture, the analysis of the documents from the public sector, in order to make a comparison and to find out which are the most evaluated by them after the empirical research.

\begin{tabular}{|c|c|c|}
\hline $\begin{array}{l}\text { Elements of management } \\
\text { culture derived from } \\
\text { corporate concepts }\end{array}$ & $\begin{array}{l}\text { Elements of management } \\
\text { culture derived from public } \\
\text { sector documents }\end{array}$ & $\begin{array}{l}\text { Elements of management } \\
\text { culture, derived from the } \\
\text { empirical study }\end{array}$ \\
\hline $\begin{array}{l}\text { - Vision, as a guiding } \\
\text { factor in the } \\
\text { management of the } \\
\text { head } \\
\text { - The values }\end{array}$ & $\begin{array}{r}\bullet \text { Openness and } \\
\text { transparency } \\
\bullet \text { Efficiency and } \\
\text { effectiveness } \\
\bullet \text { Responsibility for } \\
\text { environmental } \\
\text { protection } \\
\text { - Social responsibility }\end{array}$ & $\begin{array}{l}\text { - Responsibility } \\
\text { - Transparency } \\
\text { - Cooperation } \\
\text { - Loyalty } \\
\text { - Knowledge of the law }\end{array}$ \\
\hline $\begin{array}{l}\text { - Mentoring } \\
\text { - Respect and courtesy } \\
\text { - Communication }\end{array}$ & $\begin{array}{r}\bullet \text { Responsibility } \\
\text { - Knowledge in the field } \\
\text { of proper delegation } \\
\text { - Administrative culture } \\
\text { - Promoting innovation } \\
\text { - Strategic orientation }\end{array}$ & $\begin{array}{l}\text { - Management experience } \\
\text { - Strategic orientation } \\
\text { - Promoting innovation } \\
\text { - Keeping written } \\
\text { correspondence } \\
\text { - Conducting online } \\
\text { communications } \\
\text { - Successful negotiations } \\
\text { - Knowledge of nonverbal } \\
\text { communication }\end{array}$ \\
\hline
\end{tabular}


As can be seen from Table 7, certain elements derived from the theoretical analysis were dropped after the empirical study, because they were poorly evaluated by the surveyed managers. Elements such as - efficiency and effectiveness, environmental protection and administrative culture, embedded in the culture of the manager in the public sector, are not highly valued by business managers. Communication at the corporate level, according to the respondents, should be represented in the managerial culture of the leader most strongly through the elements - written correspondence, online communication, successful negotiation and knowledge of nonverbal communication.

Thanks to the conducted empirical research, the basic goal of the research was fulfilled, namely to establish the key elements, characteristic for the managerial culture of the Bulgarian managers.

\section{Conclusion}

Based on the analysis of the survey and the study of working hypotheses, the highest rated elements of the manager's culture can be distinguished. The evaluation of the elements was carried out on three criteria - personal qualities of the leader, professional competencies of the leader and communication culture of the leader. The highest rated elements for each criterion can be included in a list containing characteristics that a management culture must have: $\sqrt{ }$ responsibility, transparency, cooperation, loyalty, respondents over 35 years old Respondents under 35 years old, knowledge of the law, managerial experience, strategic orientation, promotion of innovations, keeping written correspondence $\sqrt{ }$ conducting online communications, successful negotiations, knowledge of nonverbal communication. The presented list includes the four elements of each criterion, which were most highly rated by the respondents, as important qualities and managerial competencies for the manager.

We can conclude that according to the study, these are the elements that should be embedded in the management culture of successful managers. Table 7 presents the derived elements of the concepts for corporate culture, the analysis of the documents from the public sector, in order to make a comparison and to find out which are the most evaluated by them after the empirical research. As can be seen from Table 7, certain elements derived from the theoretical analysis were dropped after the empirical study, because they were poorly evaluated by the surveyed managers. Elements such as - efficiency and effectiveness, environmental protection and administrative culture, embedded in the culture of the manager in the public sector, are not highly valued by business managers. Communication at the corporate level, according to the respondents, should be represented in the managerial culture of the leader most strongly through the elements - written correspondence, online communication, successful negotiation and knowledge of nonverbal communication. Thanks to the conducted empirical 
research, the basic goal of the research was fulfilled, namely to establish the key elements, characteristic for the managerial culture of the Bulgarian managers.

\section{REFERENCES}

Arthur, L., „, What Are the Elements of a Strong Corporate Culture?", Demand Media, http://smallbusiness.chron.com/elements-strong-corporateculture-15674.html

Bellot J., (2011) Defining and assessing organizational culture, Nursing Forum

Harizanova, M., N. Mironova, M. Mirchev, (2006) Management. UI Economy, pp. 96-97

Hatch M., (1997) Organization Theory: Modern, symbolic and postmodern perspectives, Oxford: Oxford University Press

Jantsch, J., „7 Elements of a Healthy and Vibrant Business Culture“, https://www.openforum.com/articles/7-elements-of-a-healthy-and-vibrantbusiness-culture/

Kroeber L, C. Kluckhohn, W. Untereiner, (1952) Culture: A Critical Review of Concepts and Definitions New York: Vintage Books

Mironova, K. Radev, (2007), Organizational behavior. Avangard Prima, Sofia

Schein, EH., (1985) Organisational culture and leadership 1st Edition San Francisco: Jossey- Bass,

Stoykov, L., (1995) Company culture and communication. IM "Economy"

Teatro. G., ,,Corporate culture: 10 elements to help drive results“, 18th of February 2013, http://leadingcompany.smartcompany.com.au/employeeengagement/corporate-culture-10-elementsto-help-drive-results/201302183702

Tylor, Edward B., (1874), Primitive culture, researches into the development of mythology, philosophy, religion, language, art and custom. New York, H. Holt and company,

Westrum R., (2004) A typology of organisational cultures Qual Saf Health care 